\title{
O sistema de gestão da qualidade no âmbito da divisão técnica de uma organização militar
}

Este trabalho apresenta, no contexto da contribuição do Sistema de Excelência Gerencial (SEG) para a eficácia operacional da Força Terrestre, a aplicação do Sistema de Gestão da Qualidade (SGQ) baseado nas NBR ISO 9001 na Divisão Técnica (DT) do Parque Regional de Manutenção/7 (Pq R Mnt/7), com o objetivo de identificar as melhorias obtidas na OM. Tal abordagem se justifica pela necessidade de utilização de ferramentas de excelência gerencial no âmbito das DT dos Parques Regionais e Batalhões de Manutenção, face às demandas de confiabilidade nos processos de planejamento, coordenação e acompanhamento da produção, rastreabilidade da informação, e de um sistema eficiente de análise crítica de processos e informações. Para tanto, realiza pesquisa documental no Pq $\mathrm{R} \mathrm{Mnt/7,} \mathrm{para} \mathrm{a} \mathrm{análise} \mathrm{da} \mathrm{implantação} \mathrm{e} \mathrm{funcionamento} \mathrm{do} \mathrm{SGQ,} \mathrm{e} \mathrm{das} \mathrm{melhorias} \mathrm{decorrentes.} \mathrm{Os} \mathrm{resultados} \mathrm{evidenciam} \mathrm{melhorias} \mathrm{de} \mathrm{gestão} \mathrm{no} \mathrm{âmbito} \mathrm{da} \mathrm{Divisão}$ Técnica, dentre as quais a realização do mapeamento de processos, o estabelecimento de pesquisas de satisfação do cliente, as melhorias implementadas na infraestrutura, a elaboração e utilização de indicadores de gestão, a realização de auditorias, a realização de reuniões de análise crítica do SGQ, os treinamentos de colaboradores, a implementação da avaliação de fornecedores, a realização de levantamento da capacidade produtiva e a disseminação da cultura da qualidade. O estudo conclui pela contribuição do SGQ baseado nas NBR ISO 9001 no âmbito da DT do Pq R Mnt/7, integrado ao SEG, para a eficácia operacional da Força Terrestre.

\section{The quality management system in the framework of the technical division of a military organization}

\begin{abstract}
This paper presents in the context of the contribution of the Business Excellence System (BES) for the operational effectiveness of the land forces, the implementation of the Quality Management System (QMS) based on ISO 9001 in the Technical Division (TD) of the Regional Park maintenance / 7 (Pq R Mnt / 7), in order to identify the improvements achieved in this Military Organization (OM). Such an approach is justified by the need to use managerial excellence tools in the Technical Division of Regional Parks and battalions Maintenance, given the reliability demands in the planning, coordination and monitoring of production, traceability of information, and an efficient system critical analysis of processes and information. The study presents documentary research in Pq R Mnt / 7, to analyze the implementation and operation of the QMS, and the resulting improvements. The results show management improvements within the Technical Division, of which the completion of the mapping process, the establishment of customer satisfaction surveys, the improvements implemented in the infrastructure, the development and use of management indicators, conducting audits, conducting critical of the QMS review meetings, training of employees, the implementation of supplier evaluation, conducting survey of production capacity and the dissemination of quality culture. The study concludes that the contribution QMS based on ISO 9001 as part TD of Pq R Mnt / 7 integrated with the BES for the operational effectiveness of the land forces.
\end{abstract}

Keywords: QMS; ISO; Military Organization; Business Excellence System.

\section{Topic: Gestão Pública}

Reviewed anonymously in the process of blind peer.

Marcelo Trigueiro de Lima

Centro Universitário do Sul de Minas, Brasil http://lattes.cnpq.br/4147295833844527

sheldonwilliamsilva@gmail.com

\section{Leila Scanfone}

Universidade Federal de Minas Gerais, Brasil

http://lattes.cnpq.br/5508482926762965

leila@unis.edu.br

\section{Sheldon William Silva}

Instituto Federal do Norte de Minas Gerais, Brasil

http://lattes.cnpq.br/5691436224279198

sheldonwilliamsilva@gmail.com
Received: 12/05/2017

Approved: 12/07/2017
Referencing this:

LIMA, M. T.; SCANFONE, L.; SILVA, S. W.. O sistema de gestão da qualidade no âmbito da divisão técnica de uma organização militar. Revista Brasileira de Administração Científica, v.8, n.2, p.159-173, 2017. DOI: http://doi.org/10.6008/SPC2179-684X.2017.002.0012 


\section{INTRODUÇÃO}

A complexidade no ambiente de trabalho de uma Divisão Técnica (DT) decorre da necessidade de confiabilidade nas informações disponíveis, da necessidade de uma equipe bem dimensionada, capacitada e experiente; da diversidade e quantidade de Produtos de Defesa (PRODE) das Organizações Militares (OM) apoiadas; da disponibilidade de recursos no tempo e quantidade necessários; e dos prazos e metas definidos pelo Escalão Superior.

A utilização de ferramentas gerenciais, a exemplo das NBR ISO 9001, no contexto da DT, torna-se fundamental para a confiabilidade, eficiência e eficácia das atividades de planejamento, coordenação e acompanhamento da Produção (manutenção e fabricação de PRODE). Nesse sentido, a análise da experiência do Pq R Mnt/7 com o SGQ baseado nas NBR ISO 9001:2008 apresenta-se como uma oportunidade de aprendizado, justificando tal abordagem.

É importante ressaltar também a contribuição do trabalho para a evolução da doutrina militar brasileira, sobretudo na Função Logística Manutenção do Exército Brasileiro, sendo oportuna a difusão das informações obtidas para as demais OM que realizam a manutenção de 3ำ Escalão (Parques Regionais e Batalhões de Manutenção), bem como para os Comandos Logísticos Regionais enquadrantes, os Arsenais de Guerra (4ํㅡsc Mnt), e os Batalhões Logísticos (2으 Esc Mnt).

Posto isto, o objetivo geral deste trabalho é apresentar as melhorias decorrentes da aplicação do SGQ baseado nas NBR ISO 9001 na DT do Pq R Mnt/7. Para isso foi realizada inicialmente uma revisão bibliográfica por meio do levantamento de conceitos doutrinários e normativos, relacionados à Qualidade, ao SGQ baseado nas NBR ISO 9001, e ao Sistema de Excelência do Exército Brasileiro. Em seguida foi desenvolvida uma pesquisa documental realizada no âmbito do Pq R Mnt/7, objetivando identificar e compreender os processos de obtenção e certificação do SGQ baseado nas NBR ISO 9001 na DT, bem como identificar as melhorias alcançadas.

\section{REVISÃO TEÓRICA}

\section{Definição de Qualidade}

A expressão 'Qualidade' assume diversos significados diferentes, através dos tempos e do enfoque utilizado. Essa variabilidade de interpretações é analisada por Garvin (1984) para o qual a qualidade pode ser interpretada como performance (medida de desempenho); funcionalidade do produto (conjunto de funções que complementam a oferta do produto); fiabilidade (probabilidade de o produto deixar de funcionar num determinado período de tempo); conformidade (adequação às especificações); durabilidade (tempo de vida do produto); serviço (rapidez, cortesia e competência no reparo do produto); aparência (estética), e imagem (percepção subjetiva de qualidade).

Para a ABNT (2005), e no contexto de Sistema de Gestão da Qualidade, o conceito de 'Qualidade' está relacionado ao 'grau no qual um conjunto de características inerentes satisfaz a requisitos'. Em notas explicativas, cita que ' $O$ termo 'qualidade' pode ser usado com adjetivos tais como má, boa ou excelente', e que 'Inerente', ao contrário de 'atribuído', 'significa a existência de alguma coisa, especialmente como uma 
característica permanente'.

\section{Histórico da Qualidade}

Ribeiro (2012) relata que, no início, era o artesão que garantia a qualidade do produto, verificando e atuando para que não houvessem defeitos na cadeia de produção. Com o decorrer do tempo, surgiu o cargo de mestre que chefiava vários artesãos e que, posteriormente, deu lugar ao cargo de inspetor, pois o trabalho de verificação de produtos era cada vez maior. A figura 1 descreve a evolução histórica da qualidade.

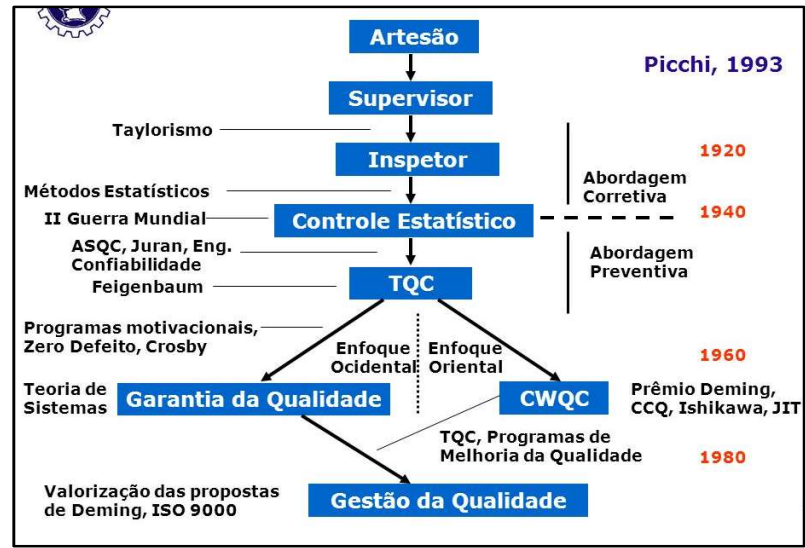

Figura 1: Evolução da gestão da qualidade. Fonte: Picchi (1993).

Trinas (2007) alerta que as diferentes abordagens filosóficas de Qualidade ainda estão em utilização nas organizações. Adotar uma filosofia da 'Qualidade Total' não significa abandonar a 'Inspeção'. Todas elas são importantes e se completam para o objetivo de se atingir a qualidade. No contexto filosófico da garantia da qualidade surge a ISO 9001, que será estudada a seguir.

\section{O SGQ baseado nas NBR ISO 9001}

A NBR ISO 9000:2005 - Sistema de Gestão da Qualidade - Fundamentos e Vocabulários define SGQ como: 'Sistema de Gestão para dirigir e controlar uma organização, no que diz respeito à Qualidade. Ribeiro (2012) conclui que "um SGQ pretende através do envolvimento de toda a organização, satisfazer as necessidades e expectativas do cliente com custos mínimos para a organização, tornando a qualidade dos produtos/serviços competitiva e lucrativa".

\section{A ISO Série 9000}

A ISO 9001 foi estabelecida em 1987, sendo um dos SGQ mais conhecidos e utilizados internacionalmente. Passou por revisões em 1994, em 2000, e recentemente em 2015. Segundo a NBR ISO 9000 (ABNT, 2005), “As normas da família NBR ISO 9000 (...) foram desenvolvidas para apoiar organizações, de todos os tipos e tamanhos, na implementação e operação de sistemas da qualidade eficazes". Segundo a supracitada norma, a Família ISO 9000 é composta ainda pelas seguintes normas:

NBR ISO 9001: estabelece os requisitos do SGQ, onde uma organização precisa demonstrar sua capacidade para fornecer produtos que atendam aos requisitos do cliente e os requisitos regulamentares aplicáveis e objetiva aumentar a satisfação 
do cliente;

NBR ISO 9004: fornece diretrizes que consideram tanto a eficácia como a eficiência do SGQ. O objetivo desta norma é melhorar o desempenho da organização e a satisfação dos clientes e das outras partes interessadas;

NBR ISO 19011: estabelece diretrizes sobre auditorias de sistemas de gestão da qualidade e ambiental (permitindo Sistemas Integrados de Gestão).

Esse consagrado SGQ estrutura-se, segundo a ABNT (2005), a partir dos oito princípios de gestão da qualidade, que estabelecem o caminho da organização, objetivando à melhoria do seu desempenho, e formam a base para as normas de SGQ na família NBR ISO 9000: Foco no cliente; Liderança; Envolvimento de pessoas; Abordagem de processo; Abordagem sistêmica para a gestão; Melhoria contínua; Abordagem factual para tomada de decisão, e Benefícios mútuos nas relações com os fornecedores.

Agudo (2012) descreve que a adoção da ISO 9001 é uma decisão estratégica, e a estrutura da norma contempla aspectos da introdução, do objetivo, da referência normativa, dos termos e definições, do SGQ, da responsabilidade da direção, da gestão de recursos, da realização do produto, e da medição, análise e melhoria.

\section{Os benefícios decorrentes da certificação ISO 9001}

Ribeiro (2012) faz uma extensa revisão da literatura, levantando os benefícios encontrados com a ISO 9001 por diversos autores, e em diferentes locais e países (Reino Unido, Taiwan, Austrália, País Basco, Canadá, Catalunha, Suécia, Nova Zelândia, e Grécia). Para o presente estudo, que trata das melhorias de uma Organização Militar do Exército Brasileiro, portanto pertencente à Administração Pública Direta, e sem fins lucrativos, pode-se reduzir a ampla análise realizada pela autora portuguesa (RIBEIRO, 2012), apresentando exemplificativamente as seguintes melhorias identificadas, como possíveis parâmetros de investigação, conforme quadro 1.

Quadro 1: Benefícios encontrados com a certificação ISO 9001.

\begin{tabular}{|c|c|}
\hline \multicolumn{2}{|c|}{ Benefícios } \\
\hline Internos & Externos \\
\hline $\begin{array}{l}\text { Melhoria nos produtos e serviços oferecidos; } \\
\text { Melhoria da eficiência a nível interna; } \\
\text { Aumento/melhoria do conhecimento a nível da qualidade; } \\
\text { Melhoria na definição de responsabilidades e funções dos } \\
\text { colaboradores; } \\
\text { Melhor resposta aos pedidos dos clientes; } \\
\text { Diminuição das auditorias dos clientes; } \\
\text { Melhoria a nível da qualidade; e } \\
\text { Melhoria nos procedimentos }\end{array}$ & $\begin{array}{l}\text { Melhoria da imagem; } \\
\text { Aumento da satisfação dos clientes; } \\
\text { Aumento da confiança do cliente; } \\
\text { Redução das reclamações de clientes; e } \\
\text { Melhoria nas relações com os clientes. }\end{array}$ \\
\hline
\end{tabular}

Dentre outros benefícios apresentados na doutrina, observa-se o reforço recíproco entre as NBR ISO 9001 e Modelo de Excelência em Gestão (MEG). Nesse sentido, Ferreira (2009) cita estudo da GAUSS CONSULTING, que comparou os Critérios de Excelência do Prêmio Nacional da Gestão Pública com as normas ISO 9001:2008, ISO 9004:2000, AS 8000:2001, OHSAS 18001, ISO 14001:2004, ISO/TS 16949:2004,e TL 9000, e ressalta a significativa cobertura dos requisitos das normas pelos Critérios de Excelência, permitindo concluir pela ação de reforço entre as Normas e o Modelo de Excelência, bem como pela facilitação do alcance 
de um pela implementação de outro.

Moura (2011) explica a complementariedade existente entre o MEG (que é mais amplo, abrangente e trata de excelência) e a norma ISO 9001 (que é básico, porque trata de requisitos mínimos). Explica o estudioso que a ISO é essencial e o MEG é rigoroso, mas o que se faz para organizar a ISO é usado para o modelo MEG. Conclui, então, que não são modelos excludentes, e sim complementares. Orienta, por fim, que a melhor prática é mirar no MEG, mas começar e manter a ISO. A figura 2 apresenta uma representação visual da equivalência:

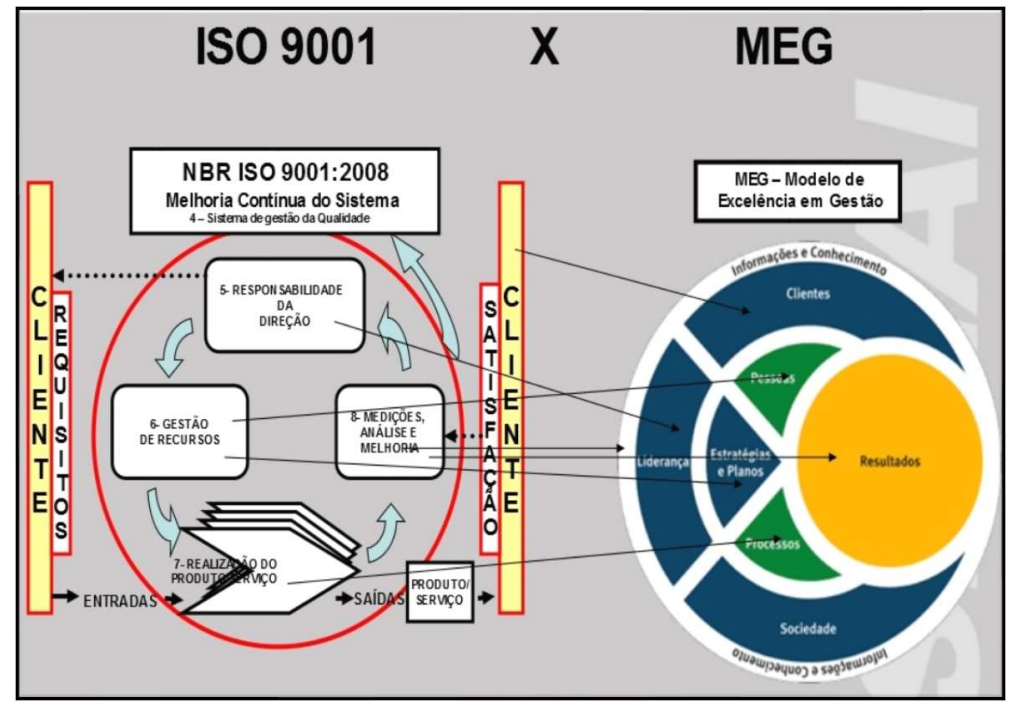

Figura 2: representação visual da equivalência.

\section{O sistema de excelência gerencial do Exército Brasileiro}

O Sistema de Excelência Gerencial do Exército Brasileiro surgiu a partir do Programa de Excelência Gerencial (PEG-EB) no ano de 2003. Conforme BRASIL (2015), objetivou melhorar a operacionalidade da tropa e atender, nas melhores condições, aos anseios de defesa e segurança da Sociedade Brasileira, e o bem-estar do público interno e de seus dependentes.

O passo seguinte foi o estabelecimento, pela Port. 220, do Cmt EB, de 20 de abril de 2007, do Sistema de Excelência no Exército Brasileiro (SE-EB), em continuidade ao Programa Excelência Gerencial (PEG-EB), esclarecendo que o SE-EB 'visa a integrar as informações gerenciais do Exército Brasileiro, para auxiliar as decisões do Comandante do Exército e do Alto-Comando do Exército, incorporando os conceitos e práticas adotadas pelo PEG-EB'.

Atualmente o Sistema de Excelência no Exército Brasileiro (SE-EB) é regulado pela Portaria no 1.266, do Comandante do Exército, de 10 de setembro de 2015, que objetiva adequá-lo às necessidades surgidas com o Processo de Transformação do Exército. Segundo consta na referida Portaria, o SE-EB deverá: 'estar alicerçado em fundamentos da gestão da excelência contemporânea e condicionado aos princípios constitucionais próprios da natureza pública das organizações'; e 'ter firme compromisso com os resultados, mediante a formulação de metas, prazos e indicadores bem definidos, para o indispensável acompanhamento na busca da efetividade na gestão do bem público e no aumento da operacionalidade da Força'.

Segundo os artigos 30 e 4을 da Portaria acima referida, o SE-EB abrange a Sistemática de Planejamento 
Estratégico do Exército (SIPLEx), o Sistema Integrado de Gestão (SIG), a Auto avaliação e Validação do Modelo de Excelência em Gestão Pública para o Exército Brasileiro (MEGP-EB), a Gestão de Projetos Estratégicos do Exército, a Gestão de Processos Organizacionais (relacionada ao mapeamento, aprimoramento e documentação dos processos organizacionais), a Racionalização Administrativa do Exército Brasileiro (relacionada à implantação da cultura de inovação com o objetivo de busca de eficiência, eficácia e efetividade da Força Terrestre), e a Capacitação (com o objetivo de buscar a melhoria contínua na gestão das OM e consolidar a aplicação da metodologia no SE-EB).

Conforme BRASIL (2015), o Exército Brasileiro participou dos estudos de elaboração do Modelo de Excelência na Gestão Pública, e para o ciclo de 2008 o EB passou a realizar a Auto Avaliação utilizando 08 (oito) Critérios de Excelência, baseados no Modelo de Excelência na Gestão Pública, customizado para o Exército Brasileiro (MEGP-EB)

\section{Caracterização da Organização Militar}

O Pq R Mnt/7 é uma organização militar do Poder Executivo Federal, subordinado à 7ạ Região Militar (7a RM), pertencente ao Comando Militar do Nordeste (CMNE) e ao Exército Brasileiro (EB). Conforme consta no Plano de Gestão (BRASIL, 2014), a missão do Pq R Mnt/7 é “Prover o apoio de manutenção de 3o escalão na área da 70 RM e de 20 escalão às OM não apoiadas pelo 14으 B Log, sediadas ou em trânsito no território da 70 RM, para contribuir com a garantia da operacionalidade da 70 RM". Segundo BRASIL (2012), a área de atuação abrange os estados do Rio Grande do Norte, Paraíba, Pernambuco e Alagoas. Possui aproximadamente 350 integrantes. Suas instalações físicas compreendem uma área construída de $10.793,41 \mathrm{~m}^{2}$, inserida numa área total de $43.125,82 \mathrm{~m}^{2}$, com oficinas e instalações de Direção e Apoio.

Os principais produtos do Pq R Mnt/7 são a manutenção e a fabricação de PRODE (de acordo com as necessidades das OM apoiadas), o fornecimento de orientações técnicas, e a capacitação dos militares das qualificações do Material Bélico, no âmbito da 7a RM. A DT do Pq R Mnt/7 é a seção do Estado-Maior da OM responsável por realizar o planejamento e o acompanhamento da produção (manutenção e fabricação) da ampla gama de PRODE identificados no quadro 2:

Quadro 2: Divisão dos PRODE por Classes.

\begin{tabular}{|l|l|l|}
\hline Classe & Discriminação & Exemplos \\
\hline II & Material de Intendência & $\begin{array}{l}\text { Porta-carregadores de fuzil e pistola, cintos, coldres, suspensórios, sacos } \\
\text { de campanha, mochilas, dentre outros. }\end{array}$ \\
\hline V & $\begin{array}{l}\text { Material de Armamento e Instrumentos } \\
\text { Óticos e de Direção e Controle de Tiro }\end{array}$ & $\begin{array}{l}\text { Pistolas, fuzis, carabinas, metralhadoras, morteiros, obuses, binóculos, } \\
\text { óculos de visão noturna, e goniômetros-bússola. }\end{array}$ \\
\hline VII & Material de Engenharia & $\begin{array}{l}\text { Redes de camuflagem, grupos geradores de energia, microtratores e } \\
\text { motosserras. }\end{array}$ \\
\hline IX & Material de Comunicações & Rádios e centrais telefônicas. \\
\hline X & Material de Motomecanização & $\begin{array}{l}\text { Viaturas administrativas, viatura operacionais blindadas, viaturas } \\
\text { operacionais não- blindadas, motocicletas, reboques diversos }\end{array}$ \\
\hline
\end{tabular}

Na estrutura da DT as funções são desempenhadas por militares dos seguintes postos/graduações: 
Chefia: 01 (um) Major/Capitão; Adjunto: 01 (um) Tenente/Subtenente; Gerentes de Manutenção: Subtenentes ou Sargentos (variando em número para cada classe de PRODE, a depender das demandas no ano de Produção). Para fins de SGQ apenas a Chefia, o Adjunto e os Gerentes de Manutenção estão atualmente no escopo da certificação ISO 9001:2008. De acordo com o Manual da Qualidade (BRASIL, 2015), a política da qualidade descreve que "A Divisão Técnica fornece serviços de planejamento e acompanhamento das atividades de manutenção e fabricação de Produtos de Defesa (PRODE) da 7ạ Região Militar, buscando a satisfação do cliente através da eficácia da melhoria contínua'.

O ambiente de trabalho da DT é caracterizado pela constante mudança de integrantes, decorrente da política que trata de movimentações de pessoal, no âmbito da Força Terrestre. ${ }^{1}$ A execução do planejamento está condicionada à liberação de recursos dos Órgãos de Direção Setorial, e da política de manutenção de PRODE estabelecida para o período, podendo variar a cada ano, e mesmo dentro do ano de produção, com reflexos nas atividades de aquisição de insumos e serviços, e consequentemente na programação da produção.

Outra especificidade da DT é a necessidade de informações fidedignas e atualizadas da produção em curso. Essas informações também devem estar disponíveis, tendo em vista possíveis desdobramentos jurídicos (a exemplo da verificação de responsabilidade em caso de acidentes) e administrativos (a exemplo dos planejamentos e análise de falhas). Os clientes estão relacionados na figura 3. Observa-se a variedade de OM apoiadas. Para cada tipo de OM há diferentes tipos de PRODE com demandas distintas de manutenção em 2으 e 3을scalão.

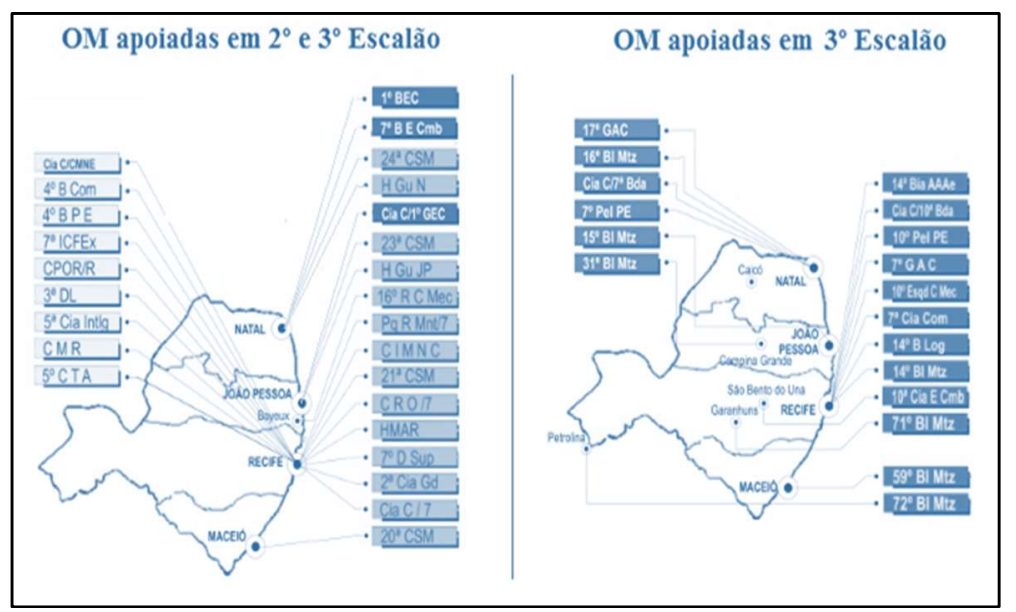

Figura 3: OMs apoiadas.

\section{Histórico do SGQ da DT do Pq R Mnt/7}

No ano de 2006 foi definido pela Direção do Pq R Mnt/7, como uma das estratégias do Plano de Gestão, a implementação e utilização da metodologia da norma ISO 9001 no SGQ da DT. Tal demanda decorreu de avaliação diagnóstica realizada na atividade-fim da OM. Segundo Brasil (2008), foram evidenciados baixa produtividade, imprecisão no Controle da Produção, dados inconsistentes da real

${ }^{1}$ Exemplificando, de agosto de 2007 (mês da certificação com as NBR ISO 9001) a outubro de 2015 já ocuparam a função de chefia da DT 06 (seis) oficiais, conforme Atas de Reunião de Análise Crítica dos anos de 2007 a 2015. 
capacidade produtiva, e planejamento inadequado.

O processo de certificação foi uma das diversas medidas adotadas para a melhoria da gestão da DT no biênio 2006-2007, das quais também constam o estabelecimento da Diretriz de Trabalho da Divisão Técnica, do Programa Excelência na Manutenção e Produção, do Projeto de Avaliação das Demandas das OM Apoiadas, da Sistemática de Suprimento do Pq R Mnt/7, e da criação da Assessoria de Gestão Organizacional (AGO).

Os recursos para a preparação da OM foram disponibilizados pela Assessoria Especial do Gabinete do Comandante do Exército (AEsp/Gab Cmt Ex), conforme Brasil (2006). O planejamento de certificação foi estabelecido em setembro de 2006, sendo reajustado conforme amadurecia o projeto. 0 quadro 3 apresenta a configuração final.

Quadro 3: Fases do processo de certificação.

\begin{tabular}{|l|l|l|}
\hline \multicolumn{1}{|c|}{ Fase } & \multicolumn{1}{|c|}{ Atividade } & \multicolumn{1}{|c|}{ Período de execução } \\
\hline 1 & Capacitação de pessoal & 2006 e 2007 \\
\hline 2 & $\begin{array}{l}\text { Divulgação do SGQ, e definição de infraestrutura e meio ambiente a ser empregado } \\
\text { no SGQ }\end{array}$ & A partir de dezembro de 2007 \\
\hline 3 & Produção da documentação adequada e adequação dos processos & Ago 2006 a Jan 2007 \\
\hline 4 & Implantação e acompanhamento do SGQ e devida geração de registros & Jan e Fev 2007 \\
\hline 5 & Auditoria interna & Fev, Mar e Abr de 2007 \\
\hline 6 & $\begin{array}{l}\text { Análise crítica das não-conformidades e proposição de ações corretivas/preventivas, } \\
\text { com a devida implementação das ações }\end{array}$ & A cada auditoria realizada \\
\hline 7 & Pré-auditoria pela BVQI & 2- quinzena de maio de 2007 \\
\hline 8 & Auditoria de certificação & 2- quinzena de agosto de 2007 \\
\hline
\end{tabular}

Fonte: Brasil (2006).

Dentre as principais capacitações de pessoal, relacionados às NBR ISO 9001, encontram-se os cursos de conhecimento do SGQ, de formação de auditores líderes e de auditores internos, de indicadores de qualidade e de produtividade, de avaliação de satisfação de clientes, de tratamento de não-conformidades, e de elaboração de documentos do SGQ.

No dia 29 de maio de 2007 ocorreu a pré auditoria de certificação, ensejando os preparativos e ajustes finais para a Auditoria de Certificação, que foi realizada pela então Bureau Veritas Certification (BVC), no dia 21 de agosto de 2007, e que resultou na recomendação à Certificação pela NBR ISO9001:2000. Em 2008 e 2009 foram realizadas as auditorias de manutenção. Em 2010 ocorreu a primeira recertificação, agora com a NBR ISO 9001:2008. Nos anos de 2011 e 2012 foram realizadas as respectivas auditorias de manutenção. No ano de 2013 ocorreu a segunda recertificação com a NBR 9001:2008. Nos anos de 2014 e 2015 foram realizadas as respectivas auditorias de manutenção.

O escopo do SGQ do Pq R Mnt/7 permanece com a mesma abrangência desde 2007: “Planejamento, coordenação e acompanhamento das atividades de manutenção e fabricação de Produtos de Defesa (PRODE) no âmbito da Divisão Técnica do Parque Regional de Manutenção/7", conforme verifica-se no Manual da Qualidade (BRASIL, 2015) e na recomendação de certificação. 


\section{RESULTADOS E DISCUSSÃO}

\section{Mapeamento de processos realizados na DT}

Observa-se nos registros de 2006, e antes da decisão de implantação da ISO 9001, o esforço inicial de escrituração dos procedimentos realizados no âmbito da DT (a exemplo da elaboração da Diretriz de Trabalho da Divisão Técnica, do Programa Excelência na Manutenção e Produção, e do Projeto de Avaliação das Demandas das OM Apoiadas). Após a decisão de certificação, observa-se o aperfeiçoamento do mapeamento de processos já direcionado à certificação, tendo como exemplos a redação do Manual da Qualidade e das Normas Operacionais das atividades de produção na Divisão Técnica.

Em 03 de janeiro de 2007 foi expedida a Ordem de Serviço no 01 da AGO, regulando a Implantação do Sistema de Gestão da Qualidade - ISO 9001:2000, na qual previa-se a produção dos demais documentos necessários ao SGQ. Dessa forma, na ocasião da Certificação, em 21 de agosto de 2007, o SGQ já dispunha de 64 (sessenta e quatro) processos efetivamente mapeados e em utilização, além do Manual da Qualidade.

O princípio da melhoria contínua impõe a realização da análise crítica do $S G Q$, bem como a revisão periódica da documentação. Desta forma, a qualidade e a quantidade de mapeamento de processos continuou evoluindo de 2007 a 2015. Conforme Brasil (2013), destacam-se nesse período a adoção de fluxogramas, e o aumento no número de documentos e de formulários, abrangendo novas situações e ampliando o controle da documentação. A tabela a seguir demonstra a evolução do mapeamento dos processos no âmbito da DT:

Tabela 1: Mapeamento de processos.

\begin{tabular}{|cccc}
\hline \multicolumn{4}{c}{ Administrativa } \\
\hline Gestão & \multicolumn{3}{c|}{} \\
\hline Ano & Documentos & Instruções de Trabalho & Formulários \\
\hline 2006 & 0 & 0 & 0 \\
\hline 2007 & 1 & 4 & 6 \\
\hline 2015 & 3 & 4 & 6 \\
\hline Gestão & & Qualidade & \\
\hline Ano & Documentos & Instruções de Trabalho & Formulários \\
\hline 2006 & 1 & 0 & 0 \\
\hline 2007 & 4 & 6 & 8 \\
\hline 2015 & 7 & 6 & 10 \\
\hline Gestão & & Produção & \\
\hline Ano & Documentos & Instruções de Trabalho & Formulários \\
\hline 2006 & 1 & 0 & 0 \\
\hline 2007 & 1 & 10 & 24 \\
\hline 2015 & 2 & 10 & 32 \\
\hline
\end{tabular}

\section{Realização de pesquisa de satisfação do cliente}

A satisfação do cliente (no caso do Pq R Mnt/7, as OM apoiadas em 2ำ e 3ำ escalões de manutenção) é um dos objetivos da certificação ISO 9001, conforme se depreende dos itens 5.2 (Foco no cliente) e 8.2.1 (Satisfação dos clientes) das NBR ISO 9001:2008. Nesse sentido, destacam-se as melhorias decorrentes do Projeto de Avaliação das Demandas das OM Apoiadas, no ano de 2006; da criação da Instrução de Trabalho I.GQ.06 - Pesquisa de Satisfação do Cliente, e do Formulário F.GQ.07 - Pesquisa de Satisfação dos Clientes, no ano de 2007; e da criação da Pesquisa de satisfação do Cliente para as atividades de Apoio Direto, em 2008. Esses instrumentos tiveram aperfeiçoamentos contínuos até 2015.

As rotinas de verificação do nível de satisfação dos clientes, bem como seu acompanhamento por 
meio do respectivo Objetivo da Qualidade 'Satisfação do Cliente', passaram a fazer parte da cultura dos integrantes da DT. As reclamações e sugestões são analisadas criticamente, sendo adotadas as providências consideradas necessárias ${ }^{2}$, e os elogios e agradecimentos são registrados e divulgados internamente para conhecimento dos integrantes do Pq R Mnt/7.

\section{Melhorias na infraestrutura}

A Ordem de Serviço № 01 da AGO, de 03 de janeiro de 2007, que regulou a Implantação do Sistema de Gestão da Qualidade - ISO 9001:2000, determinava que a DT deveria adequar as instalações de modo a proporcionar um ambiente de trabalho adequado à realização de suas tarefas (alinhado com os itens "6.3. Infraestrutura", e "6.4. Ambiente de trabalho", das NBR ISO 9001), subdividindo a tarefa em ações de definição da infraestrutura (necessidade de reforma predial; equipamentos de informática; mobiliário, etc.), dotação da DT com os equipamentos de informática solicitados, e execução das reformas previstas.

As melhorias foram implantadas e nos anos seguintes foram realizados os aperfeiçoamentos considerados necessários, com novas trocas de mobiliário, aquisições e atualização no material informatizado, e ampliação da rede informatizada, melhorando inclusive a comunicação com as Oficinas, conforme diversos registros constantes em atas de reunião de análise crítica do SGQ. Nos anos de 2008 e 2009 foram realizadas a aquisição e implantação de um sistema informatizado, projetado sob medida para as demandas diárias, denominado OPEN SGQ. Segundo BRASIL (2010), “O programa OPEN SGQ foi idealizado no final de 2008 com a finalidade de 'informatizar', através da criação de um banco de dados, as rotinas da Divisão Técnica diminuindo o trabalho de digitação e aumentando a confiabilidade e velocidade na obtenção de informações gerenciais".

\section{Elaboração e utilização de indicadores de gestão}

A melhoria contínua, como princípio basilar da ISO 9001, impõe a administração gerencial e a utilização de indicadores, que permitirão a verificação da evolução do SGQ certificado. Dessa forma, conforme BRASIL (2008), a partir de 2007 foram estabelecidos diversos indicadores para o SGQ da DT, relacionados à satisfação dos clientes, qualificação dos fornecedores, eficácia das ações corretivas, qualificação profissional, manutenções realizadas, e produtividade.

A análise de indicadores gerenciais passou a ser realizada periodicamente pela Direção, com o assessoramento da AGO e da DT, iluminando as correções de rumo e mudanças de gerenciamento necessárias. Em 2014 os Objetivos da Qualidade do SGQ (e seus respectivos indicadores) passaram a compor o Plano de Gestão da OM, como forma de alinhamento e de conjunção de esforços, no sentido de inserção dos processos críticos (além das Oportunidades de Inovação e Melhoria já usualmente lançadas) no referido planejamento estratégico. O gráfico 1 apresenta a evolução no número de indicadores relacionados ao SGQ.

\footnotetext{
${ }^{2} \mathrm{~A}$ realização de visitas prévias, e a utilização de cartão corporativo para aquisição de insumos para imprevistos foram ações decorrentes desse tipo de análise crítica, e que têm aumentado expressivamente o grau de satisfação das OM apoiadas, percebido pelo aumento de elogios recebido, referentes ao Apoio Direto.
} 


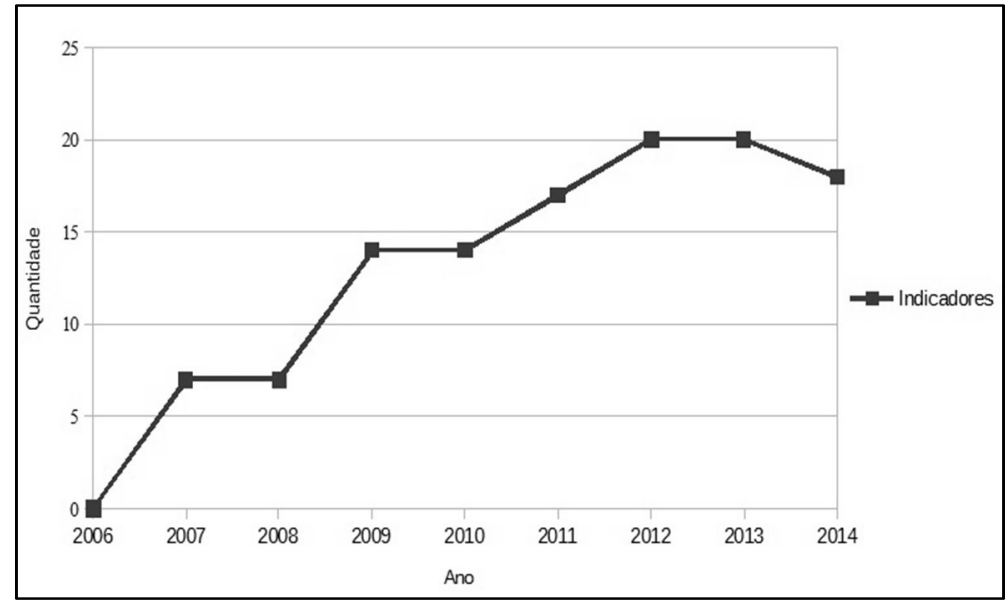

Gráfico 1: Evolução da quantidade de indicadores utilizados no SGQ.

\section{Realização de auditorias}

A Norma ISO 9001 está fundamentada no ciclo PDCA, sendo a realização das auditorias (internas e externas) o momento da verificação (Check). Sobre auditoria, Franco et al. (2007), afirma que, dentre os objetivos da auditoria, encontra-se o de "fornecer aos administradores subsídios para a obtenção de informações úteis para a tomada de decisão contribuindo ao aprimoramento da gestão".

As evidências (de conformidade ou não conformidade do SGQ) obtidas mediante a análise isenta dos auditores externos, bem como a identificação de oportunidades de melhoria e observações (possíveis em decorrência da experiência dos auditores externos), catalisaram a melhoria contínua do SGQ, conforme se depreende das diversas Atas de Reunião de Análise Crítica pós-auditorias (BRASIL, 2008, 2009, 2012, 2013, 2014).

\section{Reuniões de Análise Críticas e registro das informações}

Entre os anos de 2007 e 2015 foram realizadas cerca de 50 (cinquenta) Reuniões de Análise Crítica, tratando periodicamente sobre os resultados do SGQ, as mudanças que podem afetar o SGQ, as necessidades do SGQ, as avaliações de fornecedores críticos, a Política da Qualidade, Escopo e Exclusões, dentre tantas outras informações. Essa exigência propicia, como desdobramentos, a estabilidade dos processos, evitandose mudanças bruscas ou sem lastro técnico (dados e fatos), e permite a construção de um acervo histórico e técnico, decorrente dos registros dessas análises críticas em atas, fornecendo um precioso subsídio para o entendimento da evolução do SGQ da DT.

\section{Outras melhorias}

O SGQ da DT do Pq R Mnt/7, baseado nas NBR ISO 9001, proporcionou melhorias na gestão da DT, através do incremento de diversas atividades, antes realizadas de forma não sistêmica, ou sem embasamentos doutrinários e/ou análise crítica, a exemplo de: Treinamento de colaboradores: Atualmente a realização de treinamentos segue um planejamento anual que objetiva capacitar para o desempenho das funções (integrantes principais e substitutos), ou para o aprimoramento de determinadas capacidades de interesse para o SGQ. 
Tem-se também avaliação de fornecedores: Uma das peculiaridades do SGQ da DT do Pq R Mnt/7 é a existência de fornecedores da DT que estão também subordinados ao Diretor do Pq R Mnt/7, a exemplo das Oficinas. A avaliação desses fornecedores é realizada periodicamente, gerando um dos indicadores de interesse do SGQ. E as ações de melhoria desses colaboradores (infraestrutura ou capacitação) também tem sido objeto das estratégias do Plano de Gestão da OM, integrando as necessidades do SGQ com o planejamento estratégico da OM. A própria avaliação de fornecedores tem sido aperfeiçoada ano após ano (a I.GA.01 que trata de avaliação de fornecedores encontra-se na 5ạ versão).

Levantamento da capacidade produtiva: o conhecimento da capacidade produtiva das unidades de manutenção/fabricação, é uma das mais importantes informações para o planejamento e acompanhamento da produção. Dessa forma, os estudos sobre a capacidade produtiva (suas variáveis e perfis durante os meses do ano) realizados desde a implementação da Norma ISO 9001 na DT, buscaram tornar mais preciso o processo de Planejamento e Acompanhamento da Produção/Fabricação.

Disseminação da cultura da qualidade: os conceitos de mapeamento de processos, indicadores, análise crítica, e treinamento de colaboradores, apesar de já serem de conhecimento de grande parte do efetivo da OM, passaram a ser mais utilizados pelas demais seções da OM, mesmo que não relacionadas ao $\mathrm{SGQ}$, em virtude dos resultados positivos apresentados pela DT, bem como do rodízio de pessoal nas diversas funções da OM.

\section{CONSIDERAÇÕES FINAIS}

No contexto atual do desenvolvimento econômico e social brasileiro, a qualidade é um requisito esperado e pretendido pelas organizações, sejam da iniciativa privada, ou da Administração Pública. E as OM inserem-se nesse contexto de busca de eficiência, eficácia e efetividade. O Exército Brasileiro tem experimentado uma revolução cultural, após a implementação do Sistema de Excelência Gerencial (SE-EB) alicerçado em fundamentos da gestão da excelência. O Modelo de Excelência na Gestão adotado pelo Exército Brasileiro, é o MEG da Fundação Nacional da Qualidade customizado para atender as peculiaridades da caserna.

Caracterizam o SE-EB o contínuo investimento em capacitação de pessoal relacionado à Gestão da Qualidade, a adoção de sistemas de auto avaliação e do planejamento estratégico organizacional, o incentivo à participação das OM em Prêmios de Gestão regionais e federal, e a utilização de ferramentas da qualidade, dentre outros. No histórico de evolução da Qualidade observa-se a normatização como um dos mecanismos necessários à garantia da qualidade. A Série ISO 9000 foi estabelecida internacionalmente como uma ferramenta que evidencia a busca da qualidade (relacionada a cumprimento de requisitos) e o foco no cliente, num ambiente de melhoria contínua. No Brasil o INMETRO é o órgão responsável pela normatização de gestão da qualidade, e pela acreditação das organizações de certificação.

A certificação com as NBR ISO 9001:2008 pressupõe a existência de um SGQ, com estruturas, responsabilidades, procedimentos, e recursos definidos e adequados. Apesar da ISO 9000 ter um foco limitado dentro das organizações (o escopo é restrito a determinadas atividades e departamentos), a doutrina 
tem observado a mútua interação e complementariedade entre os princípios das NBR ISO 9001 e os preceitos do Modelos de Excelência Gerencial - MEG - (mais amplos). A partir de um deles chega-se mais facilmente ao outro ${ }^{3}$. A adoção de um SGQ baseado nas NBR ISO 9001 encontra na doutrina amplo leque de benefícios atingidos, evidenciados em estudos nacionais e internacionais, que os classificam em internos ou externos.

As atividades desenvolvidas na DT do Pq R Mnt/7 recebem interferência de fatores internos e externos, como alta rotatividade de pessoal, irregularidade no recebimento de recursos, grande diversidade de OM apoiadas e de PRODE a serem manutenidos ou fabricados, dentre outros, estabelecendo a necessidade da adoção de técnicas e ferramentas gerenciais que reduzam ou controlem os pontos fracos, e ampliem os pontos fortes existentes. Essa necessidade foi confirmada em diagnóstico interno realizado em 2006, sendo escolhida a NBR ISO 9001 para reverter o quadro de gestão ineficiente e ineficaz. O SGQ baseado nas NBR ISO 9001 (na versão 2000, à época) foi implementado em 2007 e mantido (posteriormente com a versão 2008) pelas sucessivas Direções, que entenderam pela viabilidade, aplicabilidade, e necessidade de continuidade, com os benefícios e restrições que lhes são peculiares.

Os registros da DT e da AGO, produzidos entre os anos de 2006 a 2015 e relacionados ao SGQ, evidenciam diversas melhorias de gestão da administração e da produção, no âmbito da Divisão Técnica e com irradiação para outras seções da $\mathrm{OM}$, dentre as quais foram apresentadas a realização do mapeamento de processos, o estabelecimento de pesquisas de satisfação do cliente, as melhorias implementadas na infraestrutura, a elaboração e utilização de indicadores de gestão, a realização de auditorias, a realização de reuniões de análise crítica do SGQ, os treinamentos de colaboradores, a implementação da avaliação de fornecedores, a realização de levantamento da capacidade produtiva e a disseminação da cultura da qualidade.

Em análise final, verifica-se que as melhorias são decorrentes da aplicabilidade dos princípios e da estrutura básica contida nas NBR ISO, que se coloca como um instrumento valioso ao aperfeiçoamento da gestão da DT do Pq R Mnt/7. A Gestão da Qualidade baseada na NBR ISO 9001 resulta na melhor gestão de informações, suprimento, pessoal, tempo e produção. Dessa forma, as melhorias no funcionamento da DT implicaram em melhorias na Produção. E produzir com mais eficiência e eficácia, e com os mesmos recursos, resulta no maior índice de disponibilidade dos PRODE das OM apoiadas, o que permite a manutenção do poder de combate e contribui para a eficácia operacional da Força Terrestre.

Como sugestões para futuras pesquisas, que tem como foco a evolução do Sistema de Excelência Gerencial do Exército Brasileiro, e sob o prisma de um sistema de gestão da qualidade, deve-se considerar uma análise da fase de verificação (Check) do ciclo PDCA no SE-EB; e Aplicação do SGQ baseado nas NBR ISO 9001 em organizações das Forças Armadas.

\section{REFERÊNCIAS}

ABNT. Associação Brasileira de Normas Técnicas. NBR ISO 9000: Sistemas de gestão da qualidade: Fundamentos e ABNT. Associação Brasileira de Normas Técnicas. NBR ISO vocabulário. Rio de Janeiro, 2005 9001/2008: Sistemas de Gestão da Qualidade. Rio de

${ }^{3} \mathrm{O}$ Pq R Mnt/7 encontra-se certificado com as NBR ISO 9001 desde 2007. E nos anos de 2007 e 2012 o Pq R Mnt/7 obteve troféus Prata no Prêmio da Qualidade e Gestão Pernambuco. 
Janeiro: 2008.

AGUDO, F. L.. Um estudo sobre a relação entre o sistema de gestão da qualidade ISO $9001 \mathrm{e}$ a inovação em empresas industriais do Estado de São Paulo. Dissertação (Mestrado) - Universidade do Estado de São Paulo, Bauru, 2012.

BRASIL. Exército Brasileiro. Histórico do SE-EB. Brasília: MD, 2015.

BRASIL. Exército Brasileiro. Programa Excelência Gerencial do Exército Brasileiro. Brasília: MD, 2003.

BRASIL. Exército Brasileiro. Sistema de Excelência nas Organizações Militares: SE-OM. Brasília: 2015.

BRASIL. Exército Brasileiro. Sistema de Medição do Desempenho Organizacional: IP SMDO: PEG. Brasília: MD, 2015.

BRASIL. Exército. Gabinete do Comandante. Instruções Provisórias Planejamento Estratégico Organizacional: IP PEO-PEG. Brasília: MD, 2015.

BRASIL. Parque Regional de Manutenção. Simpósio SGQ Set. Recife: 2008.

BRASIL. Parque Regional Manutenção. Ata de Reunião de Análise Crítica. Recife: 2010.

BRASIL. Parque Regional Manutenção. Ata de Reunião de Análise Crítica. Recife: 2012.

BRASIL. Parque Regional Manutenção. Ata de Reunião de Análise Crítica. Recife: 2008.

BRASIL. Parque Regional Manutenção. Ata de Reunião de Análise Crítica. Recife: 2013.

BRASIL. Parque Regional Manutenção. Ficha de Avaliação da Satisfação dos Clientes (Apoio Direto). F.GQ.10. Recife: 2014.

BRASIL. Parque Regional Manutenção. I.GA.01 Avaliação de Fornecedores. Recife: 2015.

BRASIL. Parque Regional Manutenção. I.GA.04 Identificação de Necessidades e Execução de Treinamento. Recife: 2014.

BRASIL. Parque Regional Manutenção. I.GQ.06 Pesquisa de Satisfação do Cliente. Recife: 2015.

BRASIL. Parque Regional Manutenção. Instrução SGQ da DT para Diretor 2008. Recife: 2008.

BRASIL. Parque Regional Manutenção. Manual da Qualidade. Recife: 2015.

BRASIL. Parque Regional Manutenção. Ofício n.004-06. Recife: 2006.

BRASIL. Parque Regional Manutenção. Ofício n.028-06. Recife: 2006.

BRASIL. Parque Regional Manutenção. Ofício n.049-06. Recife: 2006.

BRASIL. Parque Regional Manutenção. Ordem de Serviço no
01: AGO, Implantação do Sistema de Gestão da Qualidade: ISO9001:2000. Recife: 2007.

BRASIL. Parque Regional Manutenção. Ordem de Serviço no002: Projeto de Avaliação das Demandas das OM Apoiadas. Recife: 2006.

BRASIL. Parque Regional Manutenção. Plano de Gestão 2014-2015. Recife: 2015.

BRASIL. Parque Regional Manutenção. Relatório de Capacidade Produtiva por Seção. Recife: 2014.

BRASIL. Parque Regional Manutenção. Relatório de Gestão 2012: Prêmio de Qualidade em Gestão de Pernambuco. Recife: 2015.

BRASIL. Portaria n.1266 do Comandante do Exército. Brasília: MD, 2015.

BRASIL. Portaria n.220 do Comandante do Exército. Brasília: MD, 2007.

BRASIL. Parque Regional Manutenção. Ata de Reunião de Análise. Recife: 2009.

COSTA, P. N.. Certificação ISO 9002: estudo da percepção dos clientes internos sobre os benefícios proporcionados aos clientes externos da Gama Diesel Ltda. Monografia (Graduação em Administração) - Universidade Estadual da Paraíba, Campina Grande, 2010.

FERREIRA, A. R.. Modelo de excelência em gestão pública no governo brasileiro: importância e aplicação. In: CONGRESSO INTERNACIONAL DEL CLAD SOBRE LA REFORMA DEL ESTADO Y DE LA ADMINISTRACIÓN PÚBLICA, 14. Anais. Salvador: 2009.

FERREIRA, A. R.. Modelo de excelência em gestão pública. Revista Eixo, v.1, n.1, 2012.

FRANCO, H.; MARRA, E.. Auditoria Contábil. 4 ed. São Paulo: Atlas, 2007.

GARVIN, D. A.. What Does 'Product Quality' Really Mean?. Magazine: Fall, 1984.

GIL, A. C.. Como elaborar projetos de pesquisa. 4 ed. São Paulo: Atlas, 2002.

IAPPE, E. R.; FERREIRA, A. R.. Evolução na gestão da Diretoria de Crédito no Banco do Brasil a partir da participação no Prêmio Nacional da Gestão Pública. CONGRESSO INTERNACIONAL DEL CLAD SOBRE LA REFORMA DEL ESTADO Y DE LA ADMINISTRACIÓN PÚBLICA, 14. Anais. Salvador: 2009.

MOURA, L. R.. ISO ou MEG? Muitas empresas têm dificuldade de entender a diferença e como usar essas referências de modelo de gestão. Revista do Prodfor, p.4647, 2011.

OLIVEIRA, G. T.; MARTINS, R. A.. ISO 9001 como base para a implementação do prêmio nacional da qualidade. In: SIMPÓSIO DE ENGENHARIA DE PRODUÇÃO, 12. Anais. Bauru: UNESP, 2005.

PICCHI, F. A.. Sistema de qualidade: uso em empresas de 
construção. São Paulo: EPUSP, 1993.

PONTES, F. A. L.. Proposta de implantação de um sistema de gestão da qualidade para as $O M$ do Exército baseado na norma ISO 9001:2000. Dissertação (Mestrado) - Escola de Comando e Estado-Maior do Exército, 2003.

REIS, D. A.. Guia de estudo: Auditoria e Controle. Monografia (Pós-Graduação em Gestão em Administração Pública) Grupo Educacional UNIS, Varginha, 2015.
RIBEIRO, S. I. M. C. P.. Os benefícios e as dificuldades na certificação da qualidade: Norma NP EN ISO 9001:2008. Dissertação (Mestrado) - Instituto Politécnico do Porto, Porto, 2012.

TRINAS, H. B.. Contribuições do Programa Excelência Gerencial (PEG) para a eficácia operacional da Força Terrestre. Monografia (Pós-Graduação em Ciências Militares) - Escola de Comando e Estado-Maior do Exército, Rio de Janeiro, 2007. 